\title{
Qualidade da Silagem de Capim-Elefante (Pennisetum purpureum Schum.) Emurchecido ou Acrescido de Farelo de Mandioca ${ }^{1}$
}

\author{
Evaldo Ferrari Júnior ${ }^{2}$, Wagner Lavezzo ${ }^{3}$
}

\begin{abstract}
RESUMO - Realizou-se um experimento para avaliar a silagem de capim-elefante cv. Taiwan A-146, submetida a seis tratamentos e quatro repetições: A - capim-elefante emurchecido ao sol por 8 horas; B - capim-elefante sem emurchecimento; C - capim-elefante ( $98 \%$ ) mais farelo de mandioca (2\%); D - capim-elefante (96\%) mais farelo de mandioca (4\%); E - capim-elefante (92\%) mais farelo de mandioca (8\%) e F - capim-elefante (88\%) mais farelo de mandioca (12\%). A adição de $12 \%$ de farelo de mandioca mostrou-se mais eficiente que o emurchecimento em aumentar o teor de matéria seca da silagem. A adição de farelo de mandioca promoveu decréscimo no teor de proteína bruta, matéria orgânica, fibra em detergente neutro e hemicelulose de forma linear, porém aumentou os teores de extrativo não nitrogenado, matéria mineral e carboidratos solúveis das silagens. Os teores de ácido lático mostraram-se baixos, indicando que o farelo de mandioca não foi utilizado de forma eficiente pelos lactobacilos. Não foram observadas diferenças significativas entre as porcentagens dos ácidos acético, propiônico, butírico e lático nas silagens. O emurchecimento e a adição de farelo de mandioca podem ser utilizados como alternativas para aumentar o teor de matéria seca da silagem.
\end{abstract}

Palavras-chave: ácidos graxos voláteis, capim-elefante, emurchecimento, farelo de mandioca, silagem

\section{Quality of Elephantgrass Silage (Pennisetum purpureum Schum.) Wilted or Adding Cassava Meal}

\begin{abstract}
Silage evaluation of elephantgrass cv. Taiwan A-146 was done at Faculdade de Medicina Veterinária e Zootecnia UNESP-Botucatu. Six treatments were used with four replications as follows: A - elephantgrass with eight hours of wilting under the sun; B - elephantgrass; C - elephantgrass (98\%) plus cassava meal (2\%); D - elephantgrass (96\%) plus cassava meal (4\%); E - elephantgrass $(92 \%)$ plus cassava meal (8\%); F - elephantgrass (88\%) plus cassava meal (12\%). The efficiency meal (12\%) was greater than wilting in increasing total dry matter content. The addition of cassava led to a linear decrease in CP, OM, NDF and hemicellulose content, at the same time it increased the NFE, ASH and soluble carbohidrates contents of silages. The low levels of lactic acid showed that cassava meal was not very well processed by lactobacillus. No significant differences were observed among the acetic, propionic, butiric and lactic acid percentages of silages.
\end{abstract}

Key Words: cassava meal, elephantgrass, quality, silage, wilting

\section{Introdução}

Entre as soluções utilizadas para o armazenamento de forragens, ressalta-se a confecção de silagens uma prática relativamente simples e acessível para os criadores.

No geral, o capim-elefante deve ser cortado para ensilagem em um estádio de desenvolvimento cujo "equilíbrio nutritivo" esteja mais adequado, ou seja, quando for razoável seu rendimento de massa seca por área, bom o teor protéico e baixos os conteúdos das frações fibrosas no material. $\mathrm{O}$ excesso de umidade, quando elevado, propicia, normalmente, condições para obtenção de silagens butíricas de baixa qualidade, em que é grande a decomposição protéica, com evidente queda no valor nutritivo de tal volumoso conservado.

VILELA (1990) concluiu que o momento de corte adequado seria quando o capim-elefante estivesse com 70 dias de crescimento.

Estudo comparativo entre seis gramíneas forrageiras tropicais permitiu a TOSI (1973) verificar que o capim-elefante cv. Taiwan A-148 revelou o menor poder tampão ao ácido clorídrico, permitindo concluir que os valores do poder tampão do capim-elefante não constituíram empecilho para a ensilagem, uma vez que não impediu o rápido abaixamento do $\mathrm{pH}$ da massa armazenada.

\footnotetext{
1 Parte da tese apresentada à UNESP-Botucatu, pelo primeiro autor para obtenção do título de Doutor em Zootecnia.

2 Pesquisador Científico do Instituto de Zootecnia, Secretaria da Agricultura e Abastecimento do Estado de São Paulo. E.mail: ferrari@izsp.br

3 Professor do Departamento de Nutrição e Melhoramento Animal da UNESP-Botucatu. E.mail: waglavezzo@laser.com.br
} 
O capim-elefante, embora possua cultivares com teores de carboidratos solúveis acima de 16\% na matéria seca, como é o caso do Taiwan A-148, vem propiciando silagens razoáveis, mesmo com taxas de carboidratos solúveis abaixo dos 13 a 15\%, citados por SILVEIRA et al. (1979) e MACHADO FILHO e MÜHLBACH (1986).

Apesar de ter sido verificado que o poder tampão e os teores dos carboidratos solúveis do capimelefante podem não se constituir em fatores limitantes para obtenção de silagens adequadas, LAVEZZO (1992) alertou para o fato de que um teor mínimo de matéria seca é exigido, quando a relação entre os carboidratos solúveis e o poder tampão diminui, caso contrário fermentações indesejáveis passam a ocorrer. LAVEZZO (1985) afirmou que uma fermentação ideal no silo é esperada, quando a forragem a ser ensilada apresenta de 28 a $34 \%$ da matéria seca, sendo que, nestas condições, mesmos teores de carboidratos solúveis de 6 a $8 \%$ seriam suficientes para desencadear fermentações láticas, desde que o poder tampão não seja elevado.

No capim-elefante, tem-se verificado que o emurchecimento antes da ensilagem, muitas vezes, tem beneficiado a fermentação como um todo (LAVEZZO et al., 1990) e a lática em particular (SILVEIRA et al., 1979). Há que se considerar, porém, que o nível de desidratação não tem propiciado aqueles valores de matéria seca citados por LAVEZZO (1985) e LAVEZZO (1992), ou seja, $30 \%$ ou mais.

Por outro lado, vários autores têm verificado que, deixando o capim-elefante cortado e exposto ao sol por 6 a 12 horas, ocorre aumento no teor de matéria seca, o que, embora não permita a obtenção de material com 30 a $35 \%$ de matéria seca desejável para a ensilagem, tem propiciado a obtenção de boas silagens (MACHADO FILHO; MÜHLBACH, 1986; e VILELA, 1990).

Além do emurchecimento, outras alternativas podem ser adotadas para a ensilagem do capimelefante quando novo. Tanto o rolão de milho (ANDRADE, 1995) quanto o grão de milho triturado têm sido adicionados na ensilagem do capim-elefante, propiciando silagens com fermentações adequadas e nutricionalmente convenientes.

CONDÉ (1970), ensilando o capim-elefante Taiwan A-146 com doses que variaram de 0 a $95 \mathrm{~kg}$ de fubá/t de massa verde, concluiu que este aditivo não tem maior efeito sobre a fermentação das silagens, entretanto verificou que o fubá aumentou os teores de carboidratos solúveis e a digestibilidade in vitro da matéria seca das silagens.

Estudando o efeito do emurchecimento e da adição de raspa de mandioca sobre a ensilagem do capim-elefante, FARIAS e GOMIDE (1973) verificaram que o aditivo, utilizado na dose de $75 \mathrm{~kg} / \mathrm{t}$ de massa verde, elevou os teores de matéria seca e de carboidratos solúveis e a digestibilidade in vitro da matéria seca das silagens.

Em análises efetuadas no Departamento de Tecnologia dos Produtos Agropecuários, FCAUNESP, Botucatu, registraram-se as seguintes composições bromatológicas para o farelo de mandioca seco em estufa e em terreiro: 91,96 e $81,45 \% \mathrm{MS}$; 2,11 e $2,00 \%$ PB; 0,26 e $0,30 \%$ EE; 12,11 e $14,77 \%$ FB, 1,22 e 1,36\% MM e 79,10 e 76,90\% amido, respectivamente.

Levando-se em conta o exposto, entende-se que o farelo da mandioca desidratado, face a sua disponibilidade e a sua composição, poderia ser utilizado como aditivo durante a ensilagem do capim-elefante. Questionam-se na presente pesquisa seus reflexos sobre a qualidade da silagem (fermentação) em comparação ao emurchecimento.

\section{Material e Métodos}

A presente pesquisa foi realizada nas dependências da Faculdade de Medicina Veterinária e Zootecnia, UNESP, Campus de Botucatu.

Como material para ensilagem utilizou-se o capim-elefante (Pennisetum purpureum Schum.), cv. Taiwan A-146, proveniente de uma capineira já estabelecida e localizada em um solo classificado, por CARVALHO et al. (1991), como terra roxa estruturada distrófica. O capim-elefante foi submetido a um corte de uniformização, à altura média de $10 \mathrm{~cm}$ do solo (janeiro/97) e adubada com $100 \mathrm{~kg} / \mathrm{ha}$ de N, $100 \mathrm{~kg} / \mathrm{ha}$ de $\mathrm{P}_{2} 0_{5}$ e $60 \mathrm{~kg} / \mathrm{ha}$ de $\mathrm{K}_{2} 0$, usando-se, respectivamente, como fontes o nitrocálcio, o superfostato simples e o cloreto de potássio.

Após 70 dias de desenvolvimento, o capim-elefante foi colhido manualmente a $10 \mathrm{~cm}$ do solo, sendo picado em fragmentos de $2 \mathrm{~cm}$ em ensiladeira estacionária e submetido aos seguintes tratamentos para ensilagem: A - capim-elefante emurchecido ao sol por 8 horas; B - capim-elefante sem emurchecimento; C - capim-elefante (98\%) mais farelo de mandioca (2\%); D - capim-elefante $(96 \%)$ mais farelo de 
mandioca (4\%); E - capim-elefante $(92 \%)$ mais farelo de mandioca (8\%) e F - capim-elefante (88\%) mais farelo de mandioca (12\%). O delineamento experimental adotado foi o de blocos ao acaso com seis tratamentos e quatro repetições. Os efeitos dos níveis do farelo de mandioca foram desdobrados mediante polinômios ortogonais e a comparação entre níveis de mandioca e emurchecimento foi feita conforme DUNNETT (1955).

No processo de emurchecimento, o capim foi cortado e espalhado no campo e, após 8 horas de exposição ao sol, picado e ensilado. $\mathrm{O}$ farelo de mandioca utilizado foi desidratado ao sol (36 horas) e sua incorporação deram-se em relação à massa verde da gramínea.

O farelo de mandioca foi proveniente da Amidonaria Taquarituba-SP e consistiu de material descartado dos planos ou canais de deposição do leite de amido, proveniente da lavagem da mandioca triturada para a posterior produção de fécula, apresentando a seguinte composição química, após desidratação em terreiro: $81,45 \% \mathrm{MS} ; 2,00 \% \mathrm{~PB} ; 0,30 \% \mathrm{EE}$; $14,77 \%$ FB; $1,36 \%$ MM e 76,90\% de amido.

Como silos experimentais utilizaram-se tambores metálicos de 200 litros revestidos com sacos plásticos. As silagens permaneceram armazenadas por um período de cinco meses.

Durante a ensilagem, retiraram-se amostras do material, as quais foram divididas em duas porções, sendo uma delas armazenada em congelador a $-20^{\circ} \mathrm{C}$ e a outra seca em estufa de circulação forçada de ar, regulada a $55-60^{\circ} \mathrm{C}$.

As seguintes análises de laboratório foram realizadas no material seco, antes de ensilar e no ensilado: matéria seca (MS), proteína bruta ( $\mathrm{PB})$, extrato etéreo (EE), fibra bruta (FB), matéria mineral (MM), matéria orgânica (MO) e extrativos não nitrogenados (ENN) (por cálculo) segundo a ASSOCIATION OF OFFICIAL ANALITICAL CHEMISTS - AOAC (1975). Determinaram-se, igualmente, os teores de fibra em detergente neutro (FDN), fibra em detergente ácido (FDA), hemicelulose (HEM), celulose (CEL), lignina (LIG) e nitrogênio insolúvel em detergente ácido (NIDA), consoante GOERING e VAN SOEST (1970). Foram determinados, também, os valores do poder tampão ao $\mathrm{HCl}$ por intermédio da técnica adaptada por TOSI (1973).

Os teores de carboidratos solúveis foram quantificados conforme DUBOIS et al. (1956).

As amostras compostas frescas das silagens foram prensadas e, nos sucos extraídos, determinaram-se o $\mathrm{pH}$ em potenciômetro, os teores de nitrogênio amoniacal como porcentagem do nitrogênio total, de acordo com TOSI (1973), e os teores dos ácidos acético, propiônico, butírico e lático quantificados em cromatógrafo a gás, segundo a metodologia descrita por WILSON (1971), com modificação de BOIN (1975).

\section{Resultados e Discussão}

Os resultados das determinações químicas no capim-elefante cv. Taiwan A-146 antes e após a ensilagem são apresentados nas Tabelas 1, 2, 3, 4 e 5.

Verifica-se, na Tabela 1, que o emurchecimento do capim-elefante proporcionou aumento $(\mathrm{P}<0,05)$ na porcentagem de matéria seca (MS), o qual foi da ordem de 9,09 unidades percentuais. Notou-se, pois, que a exposição ao sol do capim cortado antes da ensilagem foi uma técnica eficiente para diminuir o teor de umidade da forragem, quando este se apresenta no melhor período para corte, o que está em consonância com os resultados de VILELA (1990) e LAVEZZO (1992).

Comparando-se os resultados obtidos de MS antes da ensilagem e da silagem (Tabelas 1 e 3), observa-se que houve aumento na mesma, com incorporação do farelo de mandioca, o que concorda com LAVEZZO (1985).

Embora o emurchecimento seja uma alternativa viável para diminuir a umidade do capim-elefante, outras técnicas também têm sido adotadas com este propósito, entre elas o uso de subprodutos como o caso do farelo de mandioca, utilizado neste estudo, que proporcionou acréscimos no teor de MS de forma linear: $\mathrm{Y}=19,05+0,4850754 \mathrm{X}$, e $\mathrm{R}^{2}=94,9^{*}$ na forragem e na silagem: $\mathrm{Y}=23,38+0,4533082 \mathrm{X}$ e $\mathrm{R}^{2}=98,3^{*}$, o que vem ao encontro às citações de LAVEZZO (1992) e HENDERSON (1993).

Não ocorreram diferenças $(\mathrm{P}>0,05)$ entre os teores de proteína bruta (PB) dos tratamentos emurchecido, nível zero, 2 e $4 \%$ de mistura de farelo de mandioca da forragem (Tabela 1) e silagem (Tabela 3 ). Considerando-se que o farelo de mandioca é pobre neste nutriente, era esperado que sua inclusão ao capim nesses níveis não originasse grande variação.

A adição de farelo de mandioca ao capim-elefante na ensilagem reduziu os teores de $\mathrm{PB}$ nas silagens: $\mathrm{Y}=7,56$ - 0,108944 X e $\mathrm{R}^{2}=71,7$ * (Tabela 3), o que pode ser atribuído ao efeito de diluição, em conseqüência da proporção de matéria seca do aditivo pobre 
Tabela 1 - Teores médios de matéria seca (MS\%), proteína bruta (PB\%), fibra bruta (FB\%), extrato etéreo (EE\%), matéria mineral (MM\%), extrativo não nitrogenado (ENN\%) e matéria orgânica $(\mathrm{MO} \%)$ da forragem

Table 1 - Average contents of dry matter (DM\%), crude protein (CP\%), crude fiber (CF\%), ether extract (EE\%), ASH (\%), nitrogen-free extract (NFE\%) and organic matter (OM\%) of forage

\begin{tabular}{|c|c|c|c|c|c|c|c|}
\hline \multirow[t]{2}{*}{ Item } & \multicolumn{6}{|c|}{$\begin{array}{c}\text { Tratamentos } \\
\text { Treatments }\end{array}$} & \multirow[t]{2}{*}{ CV $(\%)$} \\
\hline & $\mathrm{A}^{1}$ & B & $\mathrm{C}$ & $\mathrm{D}$ & $\mathrm{E}$ & $\mathrm{F}$ & \\
\hline $\mathrm{MS}(D M)$ & 27,74 & $18,65^{*}$ & $20,23 *$ & $20,93 *$ & $23,74 *$ & $24,32 *$ & 3,12 \\
\hline $\mathrm{PB}(C P)$ & 8,47 & $7,71^{\mathrm{NS}}$ & $8,78^{\mathrm{NS}}$ & $7,43^{\mathrm{NS}}$ & $6,83 *$ & $6,79 *$ & 9,67 \\
\hline $\mathrm{FB}(C F)$ & 34,93 & $37,85^{*}$ & $33,80^{\mathrm{NS}}$ & $34,71^{\mathrm{NS}}$ & $32,44 *$ & $29,81 *$ & 3,48 \\
\hline $\mathrm{EE}(E E)$ & 3,34 & $2,71 *$ & $3,00^{\mathrm{NS}}$ & $2,66^{*}$ & $2,44 *$ & $2,31 *$ & 7,03 \\
\hline $\mathrm{MM}(A S H)$ & 5,35 & $5,43^{\mathrm{NS}}$ & $6,57^{*}$ & $5,84^{\mathrm{NS}}$ & $5,87^{\mathrm{NS}}$ & $6,71 *$ & 8,44 \\
\hline $\operatorname{ENN}(N F E)$ & 47,91 & $46,30^{\mathrm{NS}}$ & $47,85^{\mathrm{NS}}$ & $49,37^{\mathrm{NS}}$ & $52,42 *$ & $54,39 *$ & 3,80 \\
\hline $\mathrm{MO}(O M)$ & 94,65 & $94,57^{\mathrm{NS}}$ & $93,43 *$ & $94,16^{\mathrm{NS}}$ & $94,13^{\mathrm{NS}}$ & $93,29 *$ & 5,34 \\
\hline
\end{tabular}

1 A - capim-elefante emurchecido; B - capim-elefante; C - capim-elefante $+2 \%$ de farelo de mandioca; $D$ - capim-elefante $+4 \%$ de farelo de mandioca; $\mathrm{E}$ - capim-elefante $+8 \%$ de farelo de mandioca e $\mathrm{F}$ - capim-elefante $+12 \%$ de farelo de mandioca.

* Significativo a $5 \%$ de probabilidade, pelo teste de Dunnett (AxB, C, D, E e F).

NS Não significativo $(P>0,05)$.

1 A - wilted elephantgrass; $B$ - elephantgrass; $C$ - elephantgrass $+2 \%$ of cassava meal; $D$ - elephantgrass $+4 \%$ of cassava meal; $E$ - elephantgrass $+8 \%$ of cassava meal and $F$ - elephantgrass $+12 \%$ cassava meal.

* Significant at $5 \%$ of probability by DUNNETT test (AxB, C, D, E and F).

NS Not significant $(P>.05)$.

Tabela 2 - Teores médios de fibra em detergente neutro (FDN\%), fibra em detergente ácido (FDA\%), hemicelulose (HEM\%), celulose (CEL\%), lignina (LIG\%), poder tampão (PT, em g/100 g MS), carboidratos solúveis (CHO\%) e nitrogênio insolúvel no detergente ácido (NIDA, \% NTOTAL) da forragem

Table 2 - Average contents of neutral detergent fiber (NDF\%), acid detergent fiber (ADF\%), hemicellulose (HEM\%), cellulose (CEL\%), lignin (LIG\%), buffer capacity (BC, emg/100 g MS), water soluble carbohydrate (WSC\%) and acid detergent insoluble nitrogen (ADIN, $\%$ total $N)$ of forage

\begin{tabular}{|c|c|c|c|c|c|c|c|}
\hline \multirow[t]{2}{*}{ Item } & \multicolumn{6}{|c|}{$\begin{array}{c}\text { Tratamentos } \\
\text { Treatments }\end{array}$} & \multirow[t]{2}{*}{ CV $(\%)$} \\
\hline & $\mathrm{A}^{1}$ & $\mathrm{~B}$ & $\mathrm{C}$ & $\mathrm{D}$ & $\mathrm{E}$ & $\mathrm{F}$ & \\
\hline $\mathrm{FDN}(N D F)$ & 71,88 & $75,32 *$ & $70,01^{\mathrm{NS}}$ & $69,11 *$ & $64,89 *$ & $60,74 *$ & 10,83 \\
\hline $\operatorname{FDA}(A D F)$ & 46,27 & $48,65 *$ & $43,06 *$ & $43,42 *$ & $43,15 *$ & $39,57 *$ & 9,26 \\
\hline $\operatorname{HEM}(H E M)$ & 25,10 & $26,67^{\mathrm{NS}}$ & $26,96 *$ & $24,93^{\mathrm{NS}}$ & $21,99 *$ & $21,17 *$ & 6,86 \\
\hline CEL (CEL) & 36,09 & $38,18 *$ & $34,36 *$ & $34,19 *$ & $32,12 *$ & $29,93 *$ & 6,74 \\
\hline $\operatorname{LIG}(L I G)$ & 6,74 & $8,31 *$ & $6,00^{\mathrm{NS}}$ & $6,60^{\mathrm{NS}}$ & $7,16^{\mathrm{NS}}$ & $6,25^{\mathrm{NS}}$ & 10,95 \\
\hline $\mathrm{PT}(B C)$ & 15,95 & $14,90^{\mathrm{NS}}$ & $15,29^{\mathrm{NS}}$ & $14,43^{\mathrm{NS}}$ & $11,42 *$ & $12,96 *$ & 6,51 \\
\hline $\mathrm{CHO}(W S C)$ & 12,04 & $13,82^{\mathrm{NS}}$ & $20,54 *$ & $25,64 *$ & $33,87 *$ & $48,48 *$ & 4,28 \\
\hline NIDA $(A D I N)$ & 0,97 & $0,92^{\mathrm{NS}}$ & $0,94^{\mathrm{NS}}$ & $0,96^{\mathrm{NS}}$ & $0,98^{\mathrm{NS}}$ & $1,07^{\mathrm{NS}}$ & 9,31 \\
\hline
\end{tabular}

1 A - capim-elefante emurchecido; B - capim-elefante; C - capim-elefante $+2 \%$ de farelo de mandioca; $D$ - capim-elefante $+4 \%$ de farelo de mandioca; $\mathrm{E}$ - capim-elefante $+8 \%$ de farelo de mandioca e $\mathrm{F}$ - capim-elefante $+12 \%$ de farelo de mandioca.

* Significativo a $5 \%$ de probabilidade, pelo teste de Dunnett (AxB, C, D, E e F).

NS Não-significativo $(P>0,05)$.

1 A - wilted elephantgrass; $B$ - elephant grass; $C$ - elephantgrass $+2 \%$ of cassava meal; $D$ - elephantgrass $+4 \%$ of cassava meal; $E$ - elephantgrass $+8 \%$ of cassava meal and $F$ - elephantgrass $+12 \%$ cassava meal.

* Significant at $5 \%$ of probability by Dunnett test (AxB, C, D, E and F).

NS Not significant $(P>05)$.

nesse nutriente. Por outro lado, este fato não ocorreu com o emurchecimento, uma vez que o teor de PB foi superior a $8 \%$, valor considerado mínimo na forragem para atender as necessidades em proteína animal (MINSON, 1990), quando há consumo satisfatório da forrageira.

A análise de regressão mostrou que a adição de quantidades crescentes de farelo de mandioca resultou em efeito linear decrescente nos teores de fibra bruta da forragem: $\mathrm{Y}=36,70$ - 0,5719828 X e $\mathrm{R}^{2}=86,8^{*}$, entretanto, não houve efeito $(\mathrm{P}>0,05)$ para silagem.

A adição de níveis crescentes de farelo de mandioca resultou em diminuição linear no teor de extrato etéreo (EE) da forragem: $Y=2,87-0,0470582 \mathrm{X}$ e $\mathrm{R}^{2}=71,7^{*}$, observando-se na silagem efeito quadrático: $\mathrm{Y}=4,90-0,236206 \mathrm{X}+0,01177372 \mathrm{X}^{2}$ e $\mathrm{R}^{2}=81,0 *$. 
Tabela 3 - Teores médios de matéria seca (MS\%), proteína bruta (PB\%), fibra bruta (FB\%), extrato etéreo (EE\%), matéria mineral $(\mathrm{MM} \%)$, extrativo não nitrogenado (ENN\%) e matéria orgânica (MO\%) das silagens

Table 3 - Average contents of dry matter (DM\%), crude protein (CP\%), crude fiber (CF\%), ether extract (EE\%), ASH (\%), nitrogen-free extract (NFE\%) and organic matter (OM\%) of silage

\begin{tabular}{|c|c|c|c|c|c|c|c|}
\hline \multirow[t]{2}{*}{ Item } & \multicolumn{6}{|c|}{$\begin{array}{c}\text { Tratamentos } \\
\text { Treatments }\end{array}$} & \multirow[t]{2}{*}{ CV $(\%)$} \\
\hline & $\mathrm{A}^{1}$ & B & $\mathrm{C}$ & D & $\mathrm{E}$ & $\mathrm{F}$ & \\
\hline $\operatorname{MS}(D M)$ & 26,61 & $23,49 *$ & $23,93 *$ & $25,30^{\mathrm{NS}}$ & $27,37^{\mathrm{NS}}$ & $28,61 *$ & 3,13 \\
\hline $\mathrm{PB}(C P)$ & 8,06 & $7,49^{\mathrm{NS}}$ & $7,81^{\mathrm{NS}}$ & $6,73^{\mathrm{NS}}$ & $6,51 *$ & $6,42 *$ & 8,11 \\
\hline $\mathrm{FB}(C F)$ & 37,95 & $38,73^{\mathrm{NS}}$ & $36,07^{\mathrm{NS}}$ & $35,56^{\mathrm{NS}}$ & $34,29 *$ & $30,96 *$ & 3,48 \\
\hline $\mathrm{EE}(E E)$ & 4,12 & $4,79 *$ & $4,83 *$ & $3,86^{\mathrm{NS}}$ & $3,84^{\mathrm{NS}}$ & $3,76^{\mathrm{NS}}$ & 6,54 \\
\hline $\mathrm{MM}(A S H)$ & 4,62 & $5,13^{\mathrm{NS}}$ & $5,91 *$ & $5,25^{\mathrm{NS}}$ & $6,08 *$ & $6,83 *$ & 7,50 \\
\hline $\mathrm{ENN}(N F E)$ & 45,26 & $43,87^{\mathrm{NS}}$ & $45,40^{\mathrm{NS}}$ & $48,61 *$ & $49,17 *$ & $51,80 *$ & 2,52 \\
\hline $\mathrm{MO}(O M)$ & 95,38 & $94,87^{\mathrm{NS}}$ & $94,09 *$ & $94,76^{\mathrm{NS}}$ & $93,92 *$ & $93,17 *$ & 6,49 \\
\hline
\end{tabular}

1 A - capim-elefante emurchecido; B - capim-elefante; C - capim-elefante $+2 \%$ de farelo de mandioca; $D$ - capim-elefante $+4 \%$ de farelo de mandioca; $E$ - capim-elefante $+8 \%$ de farelo de mandioca e $F$ - capim-elefante $+12 \%$ de farelo de mandioca.

* Significativo a $5 \%$ de probabilidade, pelo teste de Dunnett (AxB, C, D, E e F).

NS Não-significativo $(P>0,05)$.

1 A - wilted elephantgrass; $B$ - elephant grass; $C$ - elephantgrass $+2 \%$ of cassava meal; $D$ - elephantgrass $+4 \%$ of cassava meal; $E$ - elephantgrass $+8 \%$ of cassava meal and $F$ - elephantgrass $+12 \%$ cassava meal.

* Significant at $5 \%$ of probability by Dunnett test (AxB, C, D, E and F).

NS Not significant $(P>$.05).

Tabela 4 - Teores médios de fibra em detergente neutro (FDN\%), fibra em detergente ácido (FDA\%), hemicelulose (HEM\%), celulose (CEL\%), lignina (LIG\%), carboidratos solúveis (CHO\%) e nitrogênio insolúvel no detergente ácido (NIDA, \%NTOTAL) das silagens

Table 4 - Average contents of neutral detergent fiber (NDF\%), acid detergent fiber (ADF\%), hemicellulose (HEM\%), cellulose (CEL\%), lignin (LIG\%), watter soluble carbohydrates (WSC\%) and acid detergent insoluble nitrogen (ADIN, \%NTOTAL) of silages

\begin{tabular}{|c|c|c|c|c|c|c|c|}
\hline \multirow[t]{2}{*}{ Item } & \multicolumn{6}{|c|}{$\begin{array}{c}\text { Tratamentos } \\
\text { Treatments }\end{array}$} & \multirow[t]{2}{*}{ CV $(\%)$} \\
\hline & $\mathrm{A}^{1}$ & B & $\mathrm{C}$ & $\mathrm{D}$ & $\mathrm{E}$ & $\mathrm{F}$ & \\
\hline $\mathrm{FDN}(N D F)$ & 71,85 & $72,91^{\mathrm{NS}}$ & $68,83 *$ & $68,51 *$ & $64,99 *$ & $60,37 *$ & 2,16 \\
\hline $\operatorname{FDA}(A D F)$ & 47,45 & $48,26^{\mathrm{NS}}$ & $43,47 *$ & $44,60 *$ & $44,02 *$ & $41,04 *$ & 3,89 \\
\hline $\operatorname{HEM}(H E M)$ & 25,19 & $24,65^{\mathrm{NS}}$ & $25,44^{\mathrm{NS}}$ & $23,92^{\mathrm{NS}}$ & $20,97 *$ & $19,34 *$ & 4,38 \\
\hline CEL (CEL) & 37,20 & $38,17^{\mathrm{NS}}$ & $34,65 *$ & $34,60 *$ & $33,98 *$ & $30,93 *$ & 3,82 \\
\hline $\operatorname{LIG}(L I G)$ & 7,12 & $7,73^{\mathrm{NS}}$ & $6,14^{\mathrm{NS}}$ & $6,86^{\mathrm{NS}}$ & $7,28^{\mathrm{NS}}$ & $6,89^{\mathrm{NS}}$ & 8,39 \\
\hline $\mathrm{CHO}(W S C)$ & 6,74 & $7,17^{\mathrm{NS}}$ & $12,78 *$ & $13,65 *$ & $16,08 *$ & $18,44 *$ & 6,44 \\
\hline NIDA $(A D I N)$ & 1,03 & $1,00^{\mathrm{NS}}$ & $0,99^{\mathrm{NS}}$ & $1,03^{\mathrm{NS}}$ & $1,15^{\mathrm{NS}}$ & $1,11^{\mathrm{NS}}$ & 8,02 \\
\hline
\end{tabular}

1 A - capim-elefante emurchecido; B - capim-elefante; $\mathrm{C}$ - capim-elefante $+2 \%$ de farelo de mandioca; $\mathrm{D}$ - capim-elefante $+4 \%$ de farelo de mandioca; $E$ - capim-elefante $+8 \%$ de farelo de mandioca e $F$ - capim-elefante $+12 \%$ de farelo de mandioca.

* Significativo a $5 \%$ de probabilidade, pelo teste de Dunnett (AxB, C, D, E e F).

NS Não-significativo $(P>0,05)$.

1 A - wilted elephantgrass; $B$ - elephant grass; $C$ - elephantgrass $+2 \%$ of cassava meal; $D$ - elephantgrass $+4 \%$ of cassava meal; $E$ - elephantgrass $+8 \%$ of cassava meal and $F$ - elephantgrass $+12 \%$ cassava meal.

* Significant at $5 \%$ of probability by Dunnett test (AxB, C, D, E and F).

NS Not significant $(P>05)$.

A porcentagem de matéria mineral (MM) para os tratamentos emurchecido, nível zero, 4 e $8 \%$ de mistura de farelo de mandioca para forragem (Tabela 1) e emurchecida, nível zero e $4 \%$ de farelo de mandioca para silagem (Tabela 3), mostrou-se semelhante $(\mathrm{P}>0,05)$. A adição de níveis crescentes de farelo de mandioca não causou variação definida nos teores de MM da foragem, entretanto para silagem ocorreu resposta linear: $\mathrm{Y}=5,19+0,1250539 \mathrm{X}$ e $\mathrm{R}^{2}=76,3^{*}$.

Pela análise estatística efetuada não se observaram diferenças $(\mathrm{P}>0,05)$ para extrativos não nitrogenado (ENN), entre os tratamentos emurchecido, nível zero, 2 e $4 \%$ de mistura de farelo de mandioca na forragem (Tabela 1) e entre emurchecida, nível zero e $2 \%$ de mistura de farelo de mandioca na silagem (Tabela 5). 
Tabela 5 - Valores médios de $\mathrm{pH}(\mathrm{pH})$, nitrogênio amoniacal (NAMO, \%NTOTAL), ácido lático (LAT\%), ácido acético (ACE\%), ácido butírico (BUT\%) e ácido propiônico (PROP\%) das silagens

Table 5 - Average contents of $\mathrm{pH}(\mathrm{pH})$, ammoniacal nitrogen (AN \% TOTAL N), lactic acid (LAC\%), acetic acid (ACE\%), butyric acid (BUT\%) and propionic acid (PROP\%) of silage

\begin{tabular}{|c|c|c|c|c|c|c|c|}
\hline \multirow[t]{2}{*}{ Item } & \multicolumn{6}{|c|}{$\begin{array}{c}\text { Tratamentos } \\
\text { Treatments }\end{array}$} & \multirow[t]{2}{*}{$\mathrm{CV}(\%)$} \\
\hline & $\mathrm{A}^{1}$ & $\mathrm{~B}$ & $\mathrm{C}$ & $\mathrm{D}$ & E & $\mathrm{F}$ & \\
\hline $\mathrm{PH}(P H)$ & 4,32 & $4,45^{\mathrm{NS}}$ & $4,22^{\mathrm{NS}}$ & $4,40^{\mathrm{NS}}$ & $4,37^{\mathrm{NS}}$ & $4,45^{\mathrm{NS}}$ & 2,96 \\
\hline NAMO $(A N)$ & 16,54 & $17,52^{\mathrm{NS}}$ & $18,99 *$ & $17,76^{\mathrm{NS}}$ & $18,87 *$ & $18,97 *$ & 6,40 \\
\hline $\operatorname{LAT}(L A C)$ & 2,39 & $3,45^{\mathrm{NS}}$ & $3,39^{\mathrm{NS}}$ & $3,34^{\mathrm{NS}}$ & $3,44^{\mathrm{NS}}$ & $3,52^{\mathrm{NS}}$ & 29,15 \\
\hline $\operatorname{ACE}(A C E)$ & 0,40 & $0,59^{\mathrm{NS}}$ & $0,28^{\mathrm{NS}}$ & $0,35^{\mathrm{NS}}$ & $0,38^{\mathrm{NS}}$ & $0,66^{\mathrm{NS}}$ & 36,66 \\
\hline BUT (BUT) & 0,20 & $0,18^{\mathrm{NS}}$ & $0,17^{\mathrm{NS}}$ & $0,36^{\mathrm{NS}}$ & $0,35^{\mathrm{NS}}$ & $0,51^{\mathrm{NS}}$ & 38,20 \\
\hline PROP (PROP) & 0,11 & $0,14^{\mathrm{NS}}$ & $0,09^{\mathrm{NS}}$ & $0,10^{\mathrm{NS}}$ & $0,10^{\mathrm{NS}}$ & $0,11^{\mathrm{NS}}$ & 22,25 \\
\hline
\end{tabular}

1 A - capim-elefante emurchecido; B - capim-elefante; C - capim-elefante $+2 \%$ de farelo de mandioca; $D$ - capim-elefante $+4 \%$ de farelo de mandioca; $\mathrm{E}$ - capim-elefante $+8 \%$ de farelo de mandioca e $\mathrm{F}$ - capim-elefante $+12 \%$ de farelo de mandioca.

* Significativo a $5 \%$ de probabilidade, pelo teste de Dunnett (AxB, C, D, E e F).

NS Não-significativo $(P>0,05)$.

1 A - wilted elephantgrass; $B$ - elephant grass; $C$ - elephantgrass $+2 \%$ of cassava meal; $D$ - elephantgrass $+4 \%$ of cassava meal; $E$ - elephantgrass $+8 \%$ of cassava meal and $F$ - elephantgrass $+12 \%$ cassava meal.

* Significant at $5 \%$ of probability by Dunnett test (AxB, C, D, E and F).

NS Not significant $(P>.05)$.

Entre os efeitos de níveis de aditivo na forragem e na silagem, observou-se que os teores de ENN aumentaram linearmente: $\mathrm{Y}=46,51+0,6842887 \mathrm{X}$ e $\mathrm{R}^{2}=99,2 *$ e $\mathrm{Y}=44,51+0,6273491 \mathrm{X}$ e $\mathrm{R}^{2}=91,8^{*}$, respectivamente. Estas alterações poderiam ser atribuídas ao farelo de mandioca, que se caracteriza por ser muito rico em amido.

A partir dos teores de ENN verificados no material após a ensilagem, conclui-se que o farelo de mandioca foi utilizado pelas bactérias produtoras de ácido lático, o que não está de acordo com as observações de CONDÉ (1970), CORSI et al. (1971), FARIAS e GOMIDE (1973) e LAVEZZO (1992).

A adição de 2, 4, 8 e 12\% de farelo de mandioca acarretou diminuição linear: $\mathrm{Y}=94,81$ - 0,1250537 X e $\mathrm{R}^{2}=76,3^{*}$, nos teores de MO da silagem.

Para fibra em detergente neutro (FDN) não ocorreram diferenças $(\mathrm{P}>0,05)$ entre o material emurchecido e com $2 \%$ de mistura de farelo de mandioca na forragem (Tabela 2) e emurchecido e nível zero da mistura de farelo de mandioca na silagem (Tabela 4). Para os níveis de mistura efetuados, ocorreu efeito linear decrescente: $\mathrm{Y}=73,84-1,1201293 \mathrm{X}, \mathrm{e} \mathrm{R}^{2}=96,0$ *, para a forragem.

A FDN obtida para o material antes e após a ensilagem com farelo de mandioca pode permitir maior ingestão de matéria seca, conforme pode-se depreender do trabalho realizado por RESENDEetal.(1994), os quais concluíram que aumentos na ingestão de MS foram possíveis, quando houve decréscimo na quantidade de FDN da ração.
A análise estatística dos dados de fibra em detergente ácido da forragem (FDA) revelou diferenças $(\mathrm{P}<0,05)$ entre o tratamento emurchecido e os demais (Tabela 2). Na silagem (Tabela 4), tal fato não ocorreu, somente houve entre aquela com o material emurchecido e aquela sem farelo de mandioca.

Embora do ponto de vista estatístico não tenha ocorrido efeito definido nos teores de FDA da forragem e da silagem, observou-se tendência de decréscimo na FDA, quando os níveis de mistura de farelo de mandioca aumentaram. Este fato também foi verificado por ALBERTO et al. (1993) com adição de grão de sorgo moído ao capim-elefante.

O teor de hemicelulose (HEM) do tratamento emurchecido diferiu $(\mathrm{P}<0,05)$ daqueles obtidos na forragem, quando se adicionou 2,8 e $12 \%$ de farelo de mandioca (Tabela 2). Na silagem (Tabela 4) ocorreu diferença apenas para os níveis de 8 e $12 \%$ de mistura de farelo de mandioca. Na forragem e na silagem, a adição de quantidades crescentes de farelo de mandioca provocou diminuição linear: $\mathrm{Y}=27,11-0,5319504 \mathrm{X}$ e $\mathrm{R}^{2}=93,0^{*} \mathrm{e}$

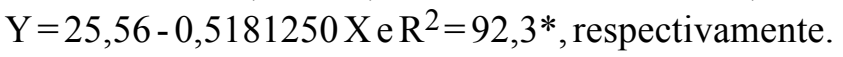

Quanto à celulose (Tabela 2), ocorreu diferença $(\mathrm{P}<0,05)$ entre o tratamento emurchecido e os demais, na forragem. Na silagem não houve diferença no teor de celulose $(\mathrm{P}>0,05)$ apenas entre o tratamento com emurchecimento e o nível zero de mistura de farelo de mandioca (Tabela 4).

A análise de regressão não se mostrou significa- 
tiva $(\mathrm{P}>0,05)$ para a adição de farelo de mandioca, tanto para forragem como para silagem.

O PT do capim-elefante estudado, com ou sem adição do farelo de mandioca, não se mostrou elevado. Dessa forma, pode-se admitir que o PT não se constituiria em empecilho para produção de silagem de boa qualidade, pois não impediria o abaixamento do $\mathrm{pH}$ da massa ensilada.

Os teores de carboidratos solúveis $(\mathrm{CHO})$ determinados na forragem e na silagem foram semelhantes $(\mathrm{P}>0,05)$ apenas nos tratamentos emurchecido e nível zero de mistura de farelo de mandioca (Tabelas 2 e 4 ), respectivamente. $O$ farelo de mandioca adicionado ao capim-elefante aumentou linearmente o teor de carboidratos da forragem: $\mathrm{Y}=14,70+2,69375 \mathrm{X}$ e $\mathrm{R}^{2}=98,8^{*}$ e da silagem: $\mathrm{Y}=9,37+0,8179633 \times$ e $\mathrm{R}^{2}=86,6^{*}$, fato também verificado por FARIAS e GOMIDE (1973).

A comparação dos conteúdos de carboidratos residuais das silagens com a forragem evidencia que esta fração foi utilizada durante a fermentação, uma vez que os teores desse nutriente apresentaram queda acentuada no material ensilado. Estes resultados sugerem que o farelo de mandioca, principalmente no nível de mistura de $12 \%$, contribuiu com quantidade substancial de substrato, concordando com FARIAS e GOMIDE (1973) e VAN ONSELEN e LOPEZ (1988), que observaram maior aproveitamento dos carboidratos solúveis contidos na silagem de capim-elefante, quando este foi misturado a raspa ou farinha de mandioca.

Não ocorreu diferença $(\mathrm{P}>0,05)$ para nitrogênio insolúvel em detergente ácido (NIDA) para o tratamento emurchecido e os demais, para forragem (Tabela 2) e silagem (Tabela 4), respectivamente.

Segundo GOERING (1976), o teor de NIDA de silagens de alfafa que sofreram superaquecimento foi maior que $0,29 \%$. Neste trabalho, os valores foram superiores, o que permite inferir que as silagens obtidas sofreram problemas de superaquecimento.

Dentro de níveis de adição de farelo de mandioca, a análise de regressão não se mostrou significativa $(\mathrm{P}>0,05)$ para forragem, porém apresentou efeito linear para silagem: $\mathrm{Y}=1,19+0,0128341 \mathrm{X}$ e $\mathrm{R}^{2}=68,4^{*}$.

$\mathrm{O}$ pH não diferiu $(\mathrm{P}>0,05)$ entre os tratamentos estudados (Tabela 5). Levando-se em conta que em uma silagem de milho de boa qualidade o $\mathrm{pH}$ deve variar de 3,8 a 4,2 (BREIREM e ULVESLI, 1960), observa-se, na Tabela 5, que apenas o tratamento com $2 \%$ de farelo de mandioca proporcionou acidez dentro dos valores preconizados na literatura.
$\mathrm{O}$ tratamento emurchecido não diferiu $(\mathrm{P}>0,05)$ do nível zero e $4 \%$ de mistura de farelo de mandioca para nitrogênio amoniacal (Tabela 5). Considerando que o nitrogênio amoniacal é produto de fermentações clostrídicas e o teor de amônia, normalmente, não deve ultrapassar valores de 11-12\% do nitrogênio total, em silagens bem conservadas (SILVEIRA, 1975), fica evidente que as silagens estudadas apresentaram fermentações indesejáveis. A análise de regressão para adição de farelo de mandioca não se mostrou significativa $(\mathrm{P}>0,05)$ para silagem.

Não ocorreram diferenças $(\mathrm{P}>0,05)$ estatísticas entre os diversos tratamentos, quando comparados ao emurchecido para ácidos lático, acético, butírico e propiônico (Tabela 5).

Os teores de ácido lático (Tabela 5) variaram de 2,35 a 3,52\% na matéria seca, o que permitiria qualificar as silagens obtidas como satisfatórias, face aos valores de 1,5 e 2,5\% e 3 a $13 \%$ de ácido lático, citados por BREIREM e ULVESLI (1960) e CATCHPOOLE e HENZELL (1971) para silagens de boa qualidade.

A adição de farelo de mandioca não afetou $(\mathrm{P}>0,05)$ os teores de ácido lático das silagens obtidas, fato também verificado por FARIAS e GOMIDE (1973) e VAN OSELEN e LOPEZ (1988).

As concentrações de ácido acético das silagens (Tabela 5) apresentaram grande variação em decorrência dos tratamentos a que foram submetidos. A literatura evidencia essa amplitude, quando se comparam os dados obtidos com os de TOSI (1973), SILVEIRA et al. (1979), LAVEZZO et al. (1983), MACHADO FILHO e MÜHLBACH (1986) e ALBERTO et al. (1993).

Foi observado efeito quadrático: $\mathrm{Y}=0,54$ $0,0926433 \mathrm{X}+0,00864905 \mathrm{X}^{2}$ e $\mathrm{R}^{2}=85,2 *$ dos níveis de mistura de farelo de mandioca ao capim-elefante nos teores de ácido acético.

As porcentagens de ácido butírico (Tabela 5) nos tratamentos estudados não foram elevadas a ponto de indicar uma fermentação clostrídica importante. No entanto, a presença de ácido butírico indica que ocorreram fermentações indesejáveis, que prejudicam assim a qualidade do produto preservado, podendo classificá-las como ruim a muito ruim, conforme LAVEZZO (1985).

Os teores de ácido propiônico (Tabela 5), com variações de 0,09 a $0,14 \%$ na matéria seca, são baixos e condizentes com os citados por LAVEZZO et al. (1983) e LAVEZZO et al. (1990), de 0,06 a $0,23 \%$ detectados em capim-elefante. 


\section{Conclusões}

O emurchecimento pela exposição do capimelefante ao sol aumentou o teor de matéria seca da forragem, favorecendo o processo de ensilagem.

A adição de farelo de mandioca proporcionou acréscimo no teor de matéria seca da silagem e, portanto, melhorou a qualidade.

O farelo de mandioca (resíduo de amidomania) aumentou os teores de matéria seca e carboidratos solúveis, entretanto, as silagens obtidas não podem ser consideradas de boa qualidade, face aos valores de nitrogênio amoniacal e ácido butírico verificados.

\section{Referências Bibliográficas}

ALBERTO, G., PORTELlA, J.S., OLIVEIRA, O.L.P. 1993. Efeito da adição de grão de sorgo moído e do emurchecimento sobre a qualidade de silagem de capim-elefante (Pennsetum purpureum, Schum.) R. Soc. Bras. Zootec., 22(1):1-11.

ANDRADE, J.B. Efeito da adição de rolão de milho, farelo de trigo e sacharina na ensilagem do capim-Elefante (Pennisetum purpureum, Schum.). Botucatu, SP: UNESP, 1995. 190p. Tese (Doutorado em Zootecnia) - Faculdade de Medicina Veterinária e Zootecnia, 1995.

ASSOCIATION OF OFFICIAL ANALITICAL CHEMISTS AOAC. 1975. Official methods of analysis. 12 ed. Washington, D.C. $1094 p$.

BOIN, C. Elephant (Napier) grass silage production, effect of addition on chemical composition, nutritive value and animal performances. Ithaca, Cornell University, 1975.215p. Tese (Doutorado Nutrição Animal) - Cornell University, 1975.

BREIREM, K., ULVESLI, O. 1960. Ensiling methods. Herb. Abst., 30(1):1-8.

CARVAlHO, W.A., ACHÁ, L.P., MORAES, M.H. Levantamento semidetalhado dos solos da Fazenda Experimental Lageado - Edgardia - Município de Botucatu SP: FCA-UNESP, Botucatu - SP, 1991. 467p.

CATCHPOOLE, V.R., HENZELL, E.F. 1971. Silage and silagemaking from tropical herbage species. Herb. Abst., 41(3):213221.

CONDÉ, A.R. Efeito da adição de fubá sobre a qualidade da silagem de capim-elefante cortado com diferentes idades. Viçosa, MG: UFV, 1970. 28p. Dissertação (Mestrado em Zooecnia) - Universidade Federal de Viçosa, 1970.

CORSI, M., FARIA, V.P., PULLICI, C.O.C. Efeito da adição de vários produtos e do murchamento prévio sobre a elevação da matéria seca do capim Napier a ser ensilado. In: REUNIÃO ANUAL DA SOCIEDADE BRASILEIRA DE ZOOTECNIA, 8, 1971, Rio de Janeiro. Anais... Rio de Janeiro: SBZ, 1971, p.52-53.

DUBOIS, M., GILLES, K.A., HAMILTON, J.K. et al. 1956. Calorimetric method for determination sugars and related substances. Anal. Chem., 28(3):350-356.

DUNNETT, C.W. 1955. A multiple comparison procedure for comparing several treatments with control. J. Americ. Stat. Assoc., 50(272):1096-1121.

FARIAS, I., GOMIDE, J.A. 1973. Efeito do emurchecimento e da adição de raspa de mandioca sobre as características da silagem de capim-elefante cortado com diferentes teores de matéria seca. Experimentiae, 16(7):131-149.

GOERING, H.K. 1976. A laboratory assessment on the frequency of overheating in commercial dehidrated alfalfa sample. J. Anim. Sci., 43(4):869-872.

GOERING, H.K., VAN SOEST, P.J. 1970. Forage fiber analysis (Apparatus, reagents, procedures and some applications). United States Department of Agriculture (Agr. Handboock n. 379). 20p.

HENDERSON, N. 1993. Silage additives. Anim. Feed Sci. and Techn., 45(1):35-56.

LAVEZZO, W. 1985. Silagem de capim-elefante. Inf. Agropec., 11(132):50-57.

LAVEZZO, W. Ensilagem do capim-Elefante. In: SIMPOSIO SOBRE MANEJO DA PASTAGEM, 10, 1992, Piracicaba. Anais... Piracicaba:FEALQ, 1992. p.169-275.

LAVEZZO, W., GUTIERRES, L.C., SILVEIRA, A.C. et al. 1983. Utilização do capim-elefante (Pennisetum purpureum, Schum.), cultivares Mineiro e Vruckwona como plantas para ensilagem. R. Soc. Bras. Zootec., 12(1):163-176.

LAVEZZO, W., LAVEZZO, O.E.N.M., BONASSI, I.A. et al. 1990. Efeito do emurchecimento, formol, ácido fórmico e solução de "Viher" sobre a qualidade de silagens de capimElefante, cultivares Mineiro e Vruckwona. Pesq. Agropec. Bras., 25(1):125-134.

MACHADO FILHO, L.C.P., MÜHLBACH, P.R.F. 1986. Efeito do emurchecimento na qualidade das silagens de capimElefante cv. Cameroun (Pennisetum purpureum, Schum.) e de milheto (Pennisetum americanum (L.) Leeke), avaliadas quimicamente. R. Soc. Bras. Zootec., 15(3):224-233.

MINSON, D.J. 1990. Forage in ruminant nutrition. 1.ed. San Diego: Academic Press. 483p.

RESENDE, F.D., QUEIROZ, A.C., FONTES, C.A.A. et al. 1994. Rações com diferentes níveis de fibra em detergente neutro na alimentação de bovídeos em confinamento. R. Soc. Bras. Zootec., 23(3):366-376.

SILVEIRA, A.C. Técnicas para produção de silagens. In: SIMPÓSIO SOBRE MANEJO DA PASTAGEM, 2, 1975, Piracicaba. Anais... Piracicaba: ESALQ, 1975. p.156-186.

SILVEIRA, A.C., LAVEZZO, W., TOSI, H. et al. 1979. Avaliação química de silagens de capim-Elefante (Pennisetum purpureum, Schum.) submetidas a diferentes tratamentos. R. Soc. Bras. Zootec., 8(2):287-300.

TOSI, H. Ensilagem de gramineas tropicais sob diferentes tratamentos. Botucatu, SP:FCMBB, 1973. 107p. Tese (Doutorado em Zootecnia) - Faculdade de Ciências Médicas e Biológicas de Botucatu, 1973.

VAN ONSELEN, V.J., LOPES, J. 1988. Efeito da adição de fontes de carboidratos e de um produto enzimático comercial na composição químico bromatológica da silagem de capimElefante (Pennisetum purpureum, Schum.). R. Soc. Bras. Zootec., 17(5):421-427.

VILELA, D. Utilização do capim-Elefante na forma de forragem conservada. In: SIMPÓSIO SOBRE CAPIM-ELEFANTE, 1990, Coronel Pacheco. Anais...Coronel Pacheco: EMBRAPA - Centro Nacional de Pesquisa de Gado de Leite, 1990. p. 89-131.

Recebido em: $11 / 10 / 00$ Aceito em: 25/04/01 